\section{The Cronkhite - Canada Syndrome: a Seldom Recognized Entity}

The Cronkhite - Canada syndrome is a rare, benign, non-neoplastic, non-hereditary condition which consists of gastrointestinal polyposis associated with alopecia, onychodystrophy, and hyperpigmentation of the skin. It usually presents with severe diarrhoea, weight loss, and other malabsorption symptoms. The age range is $31-86$ years, with a mean age of onset of 60 years. Multiple polypoid lesions are found throughout the gastrointestinal tract, with the exception of the oesophagus $(1,2)$, presenting a radiographic appearance of rounded filling defects. Microscopically, the polyps have a characteristic cystic appearance similar to that seen in juvenile polyposis.

The hair loss (usually extensive) and nail changes ( $20 \%$ loss, with dystrophy in the remainder) are an intrinsic part of the condition, and are not secondary to malabsorption $(1,2)$, but can precede or occur simultaneously with, or later than, the gastrointerstinal symptoms. Hyperpigmentation of the skin most frequently occurs on the head, neck, arms and trunk, and on microscopy consists of accumulated melanin pigment without increased melanocytes (2). Malignancy has been seen in up to $16 \%$ of the 56 reported cases (3). In these cases, most polyps showed adenomatous areas with variable dysplasia (4). The diarrhoea may resolve spontaneously, or as a result of symptomatic or antibiotic treatment, or resection of the polyp-bearing intestine (1.2.3).

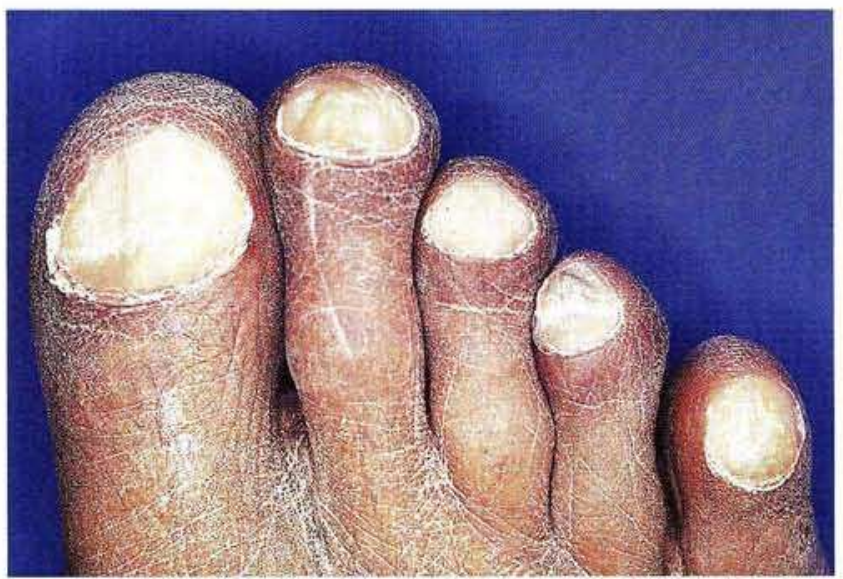

Figure 1: Onychodystrophy in the toes in Cronkhite - Canada syndrome. The toe nails show irregular transverse ridging in this case. Eighty percent of cases show onychodystrophy; the remaining $20 \%$ have total nail loss.
The aetiology of the condition is unknown. Various suggestions have been put forward, including an infective cause (3), a lack of growth factors, or a failure to respond to them (2). The syndrome is associated with a poor prognosis (3), due to the effects of malabsorption and generalized debility. It is usually managed by intravenous nutrition, total parenteral nutrition, anabolic hormones, and antibiotics (3). In the 56 reported cases, only six survived for more than two years after the diagnosis (3), cachexia and infections being the most common causes of death (2).

The authors have seen two unreported cases (Figures 1-4). The first presented with a twelve-week history of diarrhoea, intermittent blood loss, and weight loss. A carcinoma was seen in the sigmoid at colonoscopy, and this was incompletely resected initially. Following this, the patient experienced progressive total hair and nail loss. The diagnosis of Cronkhite - Canada syndrome was made during the post-mortem examination, when full clinical details were available, and the full features of the syndrome were observed. The cause of death was a massive pulmonary embolus following surgery for removal of the residual sigmoid carcinoma. The second case presented with the typical features of the syndrome, including skin pigmentation, hair loss, and onychodystrophy, as well as severe diarrhoea and weight loss over twelve months. The diagnosis was made during hospital admission. The patient died of severe bronchopneumonia with associated septicaemia, after a prolonged illness with frequent infections.

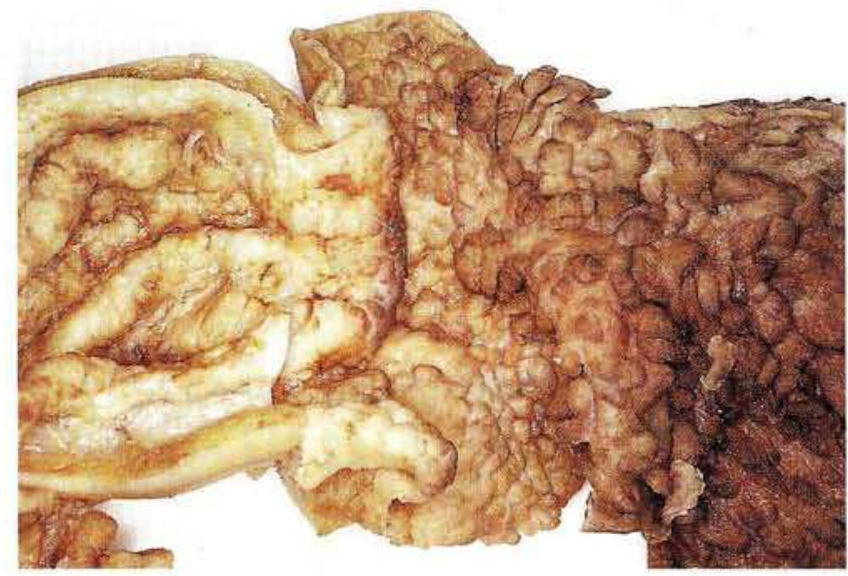

Figure 2: Stomach, pylorus, and duodenum in Cronkhite Canada syndrome. The mucosa is greatly thickened, and shows multiple polypoid nodules. 


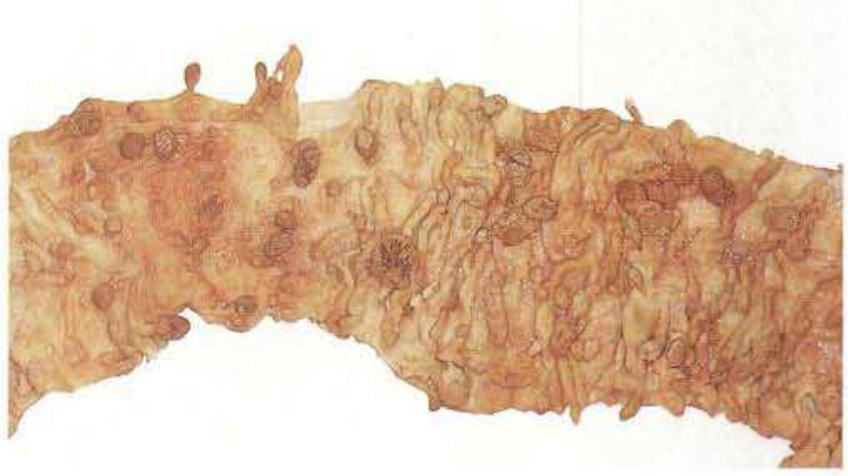

Figure 3: Multiple polyps of the colon in Cronkhite - Canada syndrome. Note the evidence of autoamputation. Gastric and colonic involvement is seen in most cases, with duodenal, jejunal and ileal involvement being present in $75 \%$ and $50 \%$ of cases, respectively.

\section{K. L. Ramsden ', H. Thompson ${ }^{2}$}

'Department of Histopathology, Maternity Hospital,

Queen Elizabeth Medical Centre, Birmingham B15 2TG, U.K.

${ }^{2}$ Department of Histopathology, General Hospital, Birmingham, U.K.

\section{References}

1. Nonomura A. Onta G, Ibata T, et al.: Cronkhite - Canada syndrome associated with sigmoid Cancer: case report and review of 54 cases of the syndrome. Acta. Pathol. Jpn. 1980; 30 (5): 825-845.

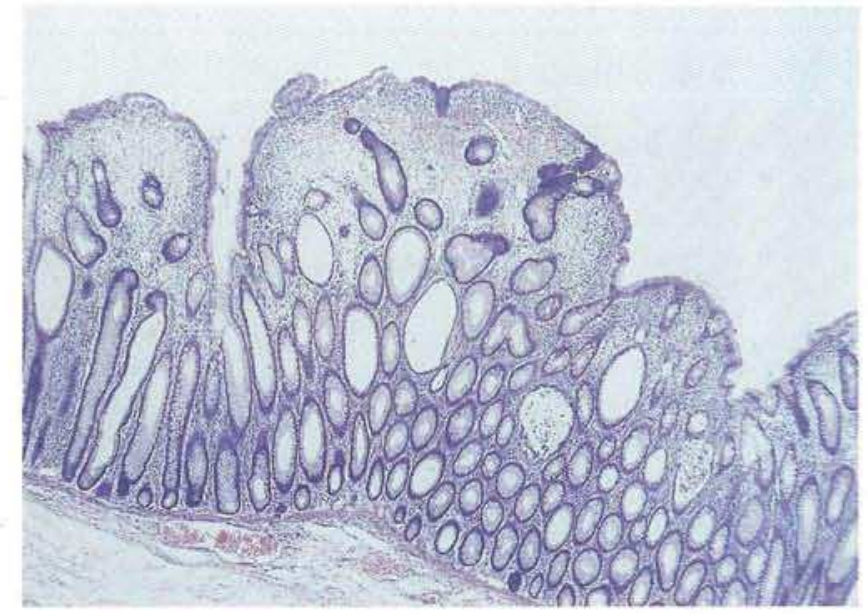

Figure 4: Typical microscopic appearance of the polyps in the Cronkhite - Canada syndrome. There is marked cystic dilation of the glands, occasional crypt abscess formation, superficial ulceration, and stromal inflammation.

2. Freeman K, Anthony PP, Miller DS, Wairn AP: Cronkhite - Canada syndrome: a new hypothesis - case report. Gut 1985; 26: 531-536.

3. Katayama $Y$, Kimura $M$, Konn $M$ : Cronkhite - Canada syndrome associated with rectal cancer and adenomatous changes in colonic polyps. Am. J. Surg. Pathol. 1985; 9: 65-71.

4. Nishiki M, Takasugi S, Kanao M, et al.: Cronkhite - Canada syndrome: a case report and analytical review of 37 other cases reported in Japan. Hiroshima J. Med. Sci. 1984; 33: 607-614. 